\title{
Sustainability assessment of refurbishment vs. new constructions by means of LCA and durability-based estimations of buildings lifespans: a new approach \\ Beatriz Palacios-Munoz ${ }^{\mathrm{a}}$, Bruno Peuportier ${ }^{\mathrm{b}}$, Luis Gracia-Villa ${ }^{\mathrm{c}}$, Belinda López-Mesa ${ }^{\mathrm{d}}$
}

a University of Zaragoza, School of Engineering and Architecture, Department of Mechanical Engineering, María de Luna 3, C.P. 50018, Zaragoza, Spain, bpalacios@unizar.es

b Mines Paristech, CES- Centre d'efficacité Energétique des Systèmes, 60 boul. St.-Michel, 75272 Paris

06, France, bruno.peuportier@mines-paristech.fr

c University of Zaragoza, School of Engineering and Architecture, Department of Mechanical Engineering, María de Luna 3, C.P. 50018, Zaragoza, Spain, lugravi@unizar.es

d University of Zaragoza, School of Engineering and Architecture, Department of Architecture, María de Luna 3, C.P. 50018, Zaragoza, Spain, belinda @unizar.es

* Corresponding author. Tel.: +34 976 762580; fax: +34 976 761000; E-mail address:

belinda@unizar.es

\begin{abstract}
A common practice in Life Cycle Assessment (LCA) of buildings is to consider a default value for their lifespan. This paper addresses the importance of estimating the lifespan of each evaluated building when refurbishment and new construction are compared, using a case study. The lifespans of the refurbished and the new buildings are estimated by applying degradation models of reinforced concrete structures. A simplified economic analysis is also performed. Two thermal performance levels are evaluated: standard and passive, in both alternatives, the refurbished and the new building. Results show that a new building can have a lifespan more than six times longer than a refurbished one. Passive refurbishment appears to be the best choice from an environmental point of view. Even if a new passive building obtains slightly better results, these can only be ensured if it is in use for a long period, in our case 210 years. This is not easy to guarantee in real practice, according to usual trends. The new passive building results to be the most cost-effective, but the same constraints regarding guaranteeing a long lifespan are applicable. The results reveal a strong dependence of LCA results on the lifespan. Its value can alter the order of preference of the solutions when comparing alternatives. There is a high potential of environmental improvement of buildings behavior by changing current practices and extending buildings' lifespan up to their physical limit.
\end{abstract}


KEYWORDS: Life Cycle Assessment; lifespan; reinforced concrete; energy consumption; refurbishment; new construction

\section{Introduction}

One of the European Union's (EU) fundamental objectives is sustainable development [1]. The contribution of buildings in environmental impacts is high. On the one hand, they account for nearly $40 \%$ of energy consumption in European Union. This is why buildings are central to the EU's energy efficiency policy [2]. On the other hand, they consume a large number of natural resources (materials, water, etc.) and represent an important source of harmful emissions to the environment. Life Cycle Assessment (LCA) provides the best framework for assessing the potential environmental impacts of products, according to the European Commission [1]. In this document, the need for more consistent data and for consensus on LCA methodologies is highlighted.

One question recently posed in the field of buildings LCA is whether or not it is more sustainable to refurbish than to rebuild [3]. Most of the literature on LCA focuses on new construction [4-8], whereas refurbishment is dealt with at a lower extent [9-12]. The comparison between the refurbishment of an existing building versus its demolition and new construction is a matter more recently studied [13-16]. The results of such a comparison depend on the building construction stage but also on the level of performance achieved after the refurbishment and the new construction, as well as on the quality and life span of the building elements.

The studies found in the literature often address the influence of the construction stage and the performance of the buildings, but that of the lifespan is seldom studied.

Lifespan is a major factor in the LCA [17] and the results are strongly dependent on it [18]. However, there is no consensus on the lifespan of buildings [7] and different values are used by the authors, e.g. 40 years [8], 50 years [19], 60 years [20] or 100 years [21]. The most commonly used value is 50 years, e.g. $[4,22,23]$. But data on real building stocks show higher values [24,25] with possibly decreasing values [26]. Increasing the life span of buildings may constitute one way to reduce their environmental impacts. When comparing refurbishment $(\mathrm{R})$ and demolition plus new building $(\mathrm{D} \& N)$, the same lifespan is usually considered for both the refurbished and the new building, and a methodology to determine this value is often not considered, but a default value is chosen instead.

To properly determine the lifespan is especially important when comparing $\mathrm{R}$ and $\mathrm{D \& N}$ because the construction stage impacts play a major role. The main advantage of $\mathrm{R}$ compared to D\&N is that $\mathrm{R}$ allows 
to avoid most construction stage impacts by means of using already existing elements. As a counterpart, the difference in the durability between the new and the refurbished building must be taken into account, to make a fair comparison. This second issue is often unaddressed in the literature. In this paper we claim the importance of this issue in the analysis and the results.

A building is made of different elements such as walls, ceilings, windows, etc. Those elements have different lifespan values. When a LCA of a whole building is done, a lifespan value for the complete building should be introduced. The general accepted criterion is to take the value of the structure lifespan as the one for the complete building [27] as all the other elements depend on its stability.

To evaluate the structure lifespan, and therefore that of the building, the methodology proposed by [51] for reinforced concrete (RC) structures is applied here. This methodology is based on the degradation models of this type of structures.

A building structure is exposed to multiple external actions often classified as physical, mechanical and chemical ones [28]. Environmental factors can cause several degradation phenomena in the reinforced concrete (corrosion, alkali-aggregate reaction, erosion, leaching, chemical attack, etc.), and they can occur simultaneously. The degree of knowledge about the different phenomena is diverse. According to Budelmann [29], the main concrete damage mechanisms in above ground RC structures are: (i) corrosion (induced by chloride or $\mathrm{CO}_{2}$ ) and (ii) alkali aggregate reaction (AAR). In this paper, just the corrosion induced by $\mathrm{CO}_{2}$ is considered among the wide amount of degradation phenomena.

Reinforcement corrosion is a major cause for degradation of existing RC structures [30]. It leads to several damage types that influence the structure physical lifespan, among others, the reduction of rebar section, the bonding loss between steel and concrete and the cracking of concrete cover due to the increase in volume of the oxides with respect to the original volume of the parent steel [31]. The corrosion phenomena is considered as a two-stage process: (i) corrosion initiation stage; and (ii) corrosion propagation stage [32].

The carbonation of cementitious materials is driven by carbon dioxide $\left(\mathrm{CO}_{2}\right)$ in the air. The depth of the carbonated cement concrete front increases with time. When it reaches the reinforced layer, corrosion is likely to occur because steel bars are not passivated any more [30]. The time when corrosion is likely to start is called initiation time, $t_{i .}$. This $t_{i}$ depends on a wide range of parameters (humidity, temperature, concrete cover, porosity, etc.). The combination of concrete quality and concrete cover thickness is apparently the most important parameter that controls the rate of carbonation ingress [33]. 
The objective of this paper is to evaluate the influence of lifespan in the comparative LCAs of a complete building considering $\mathrm{R}$ and D\&N scenarios. To address this question, both alternatives are compared in a case study considering two performance levels (standard and passive).

\section{Material and methods}

In this paper, a comparison between $\mathrm{R}$ and $\mathrm{D} \& \mathrm{~N}$ is performed in a case study considering its estimated value of lifespan and two performance levels. One is the standard performance corresponding to the coming Spanish regulation [34] and the other corresponds to a very low energy consumption performance. In the case of the standard performance, the project of the future Spanish regulation is taken as a reference as it sets the requirements of a nearly zero energy consumption building. We name this level as standard (S). In the very low energy consumption case, the Passive House standard [35] limit for heating and cooling demand is used, i.e. less than $15 \mathrm{kWh} / \mathrm{m}^{2}$. We name this level as passive $(\mathrm{P})$. The lifespans of the refurbished and the new buildings are estimated adapting the methodology proposed by [51] for reinforced concrete structures. Specifically, the following steps are taken.

(i) First of all, the case study is defined, including the selection of the existing building, the refurbishment operation and the new construction characteristics (section 2.1). The selected refurbishment operations are techniques currently applied in residential buildings in Spain. The difference between the two refurbishment options is just the insulation thickness and the windows to obtain different performance levels. The rest of the needed materials and operations are similar to avoid disturbances in the results comparison.

In the case of the new building, the same volume, living area and architectural configuration as the original ones are considered. Current building solutions and techniques in Spain are considered to define the building characteristics. The difference between the solution with standard behaviour and passive one is the insulation thickness and the windows characteristics.

(ii) Thermal behaviour is analysed to evaluate the use stage impacts of every solution. Thermal dynamic simulations using COMFIE Software [36] are carried out to obtain the heating and cooling demand of the original building, the two refurbishment alternatives and the two new building alternatives. The operational conditions defined in the Spanish regulation [34] are considered to calculate thermal loads: internal temperature in summer and winter, ventilation, electricity and equipment loads, etc.

To obtain the consumption, systems are included in a simplified way by considering the efficiency of the reference systems provided in the regulation. The same systems are considered for the refurbished and the 
new building and both in the standard and passive performance. This decision is taken in order not to disturb results because of systems, as every system could be implemented in all the solutions.

(iii) The lifespan of the existing building (and therefore, the refurbished one) and of the new building are estimated (section 2.2).

(iv) LCAs of the different options are done taking into account the predicted lifespan (section 2.3).

(v) Economic estimation are undertaken, and solutions are evaluated in terms of cost-effectiveness (section 2.4).

\subsection{Case study}

\subsubsection{Original building}

The case study consists of a residential block built in 1956 in Zaragoza (Spain). The building has eight floors and two dwellings per floor, even in the ground level. The heated and cooled surface is $1257.44 \mathrm{~m}^{2}$. The structure is made of reinforced concrete. The slabs also include ceramic elements to lighten them. The external walls consist of two layers of brick without air chamber between them and a ceramic tile cladding on one of the façades and mortar plaster on the rest of them, with no insulation layer. The building has a tile roof without thermal insulation and the windows are of wood frame with single glazing.

The yearly heating and cooling demand of the original building are $74 \mathrm{~kW} \cdot \mathrm{h} / \mathrm{m}^{2}$ and $26 \mathrm{~kW} \cdot \mathrm{h} / \mathrm{m}^{2}$, respectively.

The structure consists of three multi-storey frames with a span between them of $4.10 \mathrm{~m}$ and a span between beams of $4.00 \mathrm{~m}$. All the beams are considered to be of the same cross section of $400 \mathrm{~mm}$ width - $600 \mathrm{~mm}$ height, with a concrete cover of $40 \mathrm{~mm}$. Tensile and compressive rebars areas are $2591.82 \mathrm{~mm}^{2}$ and $157.08 \mathrm{~mm}^{2}$, respectively. The beams are considered to be under simple bending with a maximum supported moment of $140 \mathrm{kN} \cdot \mathrm{m}$. The material properties used for the estimations are those of commonly used materials in the 60's in Spain, which were obtained from the codes of that time and are shown in

Table 1.

Table 1 Material properties of original and new building structure

\begin{tabular}{|c|c|c|c|c|c|c|c|c|}
\hline \multirow[t]{2}{*}{ Material } & \multicolumn{4}{|l|}{ Existing } & \multicolumn{4}{|l|}{ New } \\
\hline & $\mathrm{f}_{\mathrm{d}}[\mathrm{MPa}]$ & $\gamma$ & $\mathrm{E}_{\mathrm{c}}[\mathrm{MPa}]$ & $\mathrm{f}_{\mathrm{ctm}}[\mathrm{MPa}]$ & $\mathrm{f}_{\mathrm{d}}[\mathrm{MPa}]$ & $\gamma$ & $\mathrm{E}_{\mathrm{c}}[\mathrm{MPa}]$ & $\mathrm{f}_{\mathrm{ctm}}[\mathrm{MPa}]$ \\
\hline Concrete & $11.77^{(2)}$ & 1.5 & $22983^{(1)}$ & $1.50^{(1)}$ & 25 & 1.5 & $30000^{(1)}$ & $2.20^{(1)}$ \\
\hline Inner rebars & $117.68^{(2)}$ & 1.15 & $180000^{(2)}$ & - & 500 & 1.15 & 200000 & - \\
\hline
\end{tabular}




\subsubsection{Refurbishment}

The refurbishment operation consists of adding exterior thermal insulation in the façade and in the roof. The ground floor in contact with the sanitary chamber is also insulated. The windows are replaced for new ones with better thermal characteristics. Some materials must be demolished or replaced to execute the refurbishment operation. The difference between the option that just fulfils the regulation and the option that fulfils the very low consumption standard is the insulation thickness as well as the type of windows.

In the case of the standard energy refurbishment (SR) that fulfils the regulation, the thickness of the glass wool that is added in the façade, roof and ground floor is $10 \mathrm{~cm}$. The windows are of wood frame with double glazing $6 / 16 / 6$ with argon $\left(\mathrm{U}=1.85 \mathrm{~W} / \mathrm{m}^{2} . \mathrm{K}\right)$. In the case of the passive energy refurbishment (PR), the thickness of the glass wool added in the façade, roof and ground floor is $10 \mathrm{~cm}, 19 \mathrm{~cm}$ and 18 $\mathrm{cm}$, respectively. The windows are of wood frame with triple low emissivity glazing with argon $(\mathrm{U}=1.09$ $\left.\mathrm{W} / \mathrm{m}^{2} \cdot \mathrm{K}\right)$.

The heating and cooling demand of SR are $30 \mathrm{kWh} / \mathrm{m}^{2}$ and $7 \mathrm{kWh} / \mathrm{m}^{2}$, respectively. The heating and cooling demand of PR are $15 \mathrm{kWh} / \mathrm{m}^{2}$ and $13 \mathrm{kWh} / \mathrm{m}^{2}$, respectively. The cooling load would be much lower considering that people open their windows at night in summer more than the operational conditions of the regulation, that are considered here, represent.

The heating system is a natural gas boiler, with an efficiency equal to 0.92 , and an electric heat pump for the cooling, with EER (Energy efficiency ratio) equal to 2.00. Hot water is produced by solar thermal energy $(60 \%)$ and natural gas boiler $(40 \%)$. As previously exposed, those are the efficiency values of the reference systems in the Spanish regulation.

The structure of the original building is maintained, and no structural intervention is considered.

\subsubsection{New building}

For the new building the same volume, living area and distribution is considered in order to be able to compare solutions. As the building is protected by a heritage regulation, the same architectural configuration must be ensured.

The new building structure is also of reinforced concrete. The slabs additionally include polystyrene pieces to lighten them and they are finished with ceramic tiles laid on mortar. The external walls are made of concrete blocks with external insulation of glass wool covered with mortar. The internal layer is finished with gypsum. The building has a traditional tile roof insulated with glass wool. 
The internal walls of the building are made of concrete blocks with glass wool and gypsum.

As in the case of the refurbishment, the difference between the demolition plus standard new building $(\mathrm{SD} \& \mathrm{~N})$ and the demolition plus passive new building $(\mathrm{PD} \& \mathrm{~N})$, are the insulation layer thickness and the windows. In the case of SD\&N, the thicknesses of the glass wool in the façade, roof and ground floor are $17 \mathrm{~cm}, 20 \mathrm{~cm}$ and $10 \mathrm{~cm}$, respectively. The windows are of wood frame with double glazing 6/16/6 with $\operatorname{argon}\left(\mathrm{U}=1.85 \mathrm{~W} / \mathrm{m}^{2} . \mathrm{K}\right)$. In the case of the PD\&N, the thicknesses of the glass wool in the façade, roof and ground floor is $11 \mathrm{~cm}, 23 \mathrm{~cm}$ and $22 \mathrm{~cm}$, respectively. The windows are of wood frame with triple low emissivity glazing with $\operatorname{argon}\left(\mathrm{U}=1.09 \mathrm{~W} / \mathrm{m}^{2} . \mathrm{K}\right)$.

The heating and cooling demand of the new building according to the regulation are $27 \mathrm{kWh} / \mathrm{m}^{2}$ and 6 $\mathrm{kWh} / \mathrm{m}^{2}$, respectively. In the passive building the heating and cooling demand are $15 \mathrm{kWh} / \mathrm{m}^{2}$ and 12 $\mathrm{kWh} / \mathrm{m}^{2}$, respectively.

The considered heating and cooling systems are similar to those of the refurbished building (natural gas boiler with 0.92 efficiency, and heat pump with EER of 2.00). Hot water is produced by solar thermal energy $(60 \%)$ and natural gas boiler $(40 \%)$.

The considered structure is similar to that of the original building. To simplify, all the beams in the new building are considered to be of the same cross section of $300 \mathrm{~mm}$ width - $350 \mathrm{~mm}$ height, with a concrete cover of $30 \mathrm{~mm}$. Tensile and compressive rebar areas are $1256.64 \mathrm{~mm}^{2}$ and $157.08 \mathrm{~mm}^{2}$, respectively. It is supposed that all the beams need to support the same load (maximum bending moment of $140 \mathrm{kN} \cdot \mathrm{m}$ ). Material properties fulfil structural regulation requirements [39] and are showed in Table 1.

\subsection{Determining the lifespan}

As already exposed, the considered building lifespan is that of its structure. In this paper, we consider the degradation phenomenon of corrosion due to carbonation since it is the most frequent one.

The methodology followed is the one defined in [51], for this type of degradation.

The applied method is based on iterative structural calculations, in which the mechanical characteristics are updated in every step according to the degradation model. In this case, the iteratively updated parameter is the rebar section that decreases as the corrosion increases. It must be noted that corrosion can also lead to other mechanical effects that influence the lifespan, such as the bonding loss between steel and concrete, and the cracking of concrete cover due to the increase in volume of the oxides with respect to the original volume of the parent steel [31]. However, these effects are not considered here due to the scope of this paper which is just to provide a rough value that can be used in LCA. 
Corrosion is a localized phenomenon and occurs in specific structural elements (i.e. a beam or a column). To extend the method to a whole building some simplifications have been made in order to narrow the problem. On the one hand, the different structural elements of the building are exposed to environments with different levels of aggressiveness (interior, exterior, etc.) and corrosion damage might not be the same for all of them. This study focuses just on beams because they are more sensitive to rebar section losses than columns. Beams are classified, depending on their exposure conditions, into: indoor, outdoor, below the roof or in contact with sanitary floor slab. Therefore, the degradation model is applied to four types of beams.

The shortest value that is obtained is considered as the building lifespan. This can lead to a lower value than the potential one, but it remains on the security side. This same hypothesis is used for both $\mathrm{R}$ and D\&N.

Two improvements are made to the methodology proposed by [51]. The first of them is explained next. To model the initiation time of corrosion, the model proposed in the fib Model Code (MC2010) [40] is applied, instead of the model proposed by V.-L. Ta et al. [30] that was used in [51]. This is because the model proposed in MC2010 provides statistical data of the distributions and deviations of the input parameters. This allows to calculate the deviation of the final result as well as the probability associated to a certain data of lifespan which is important due to the considerable uncertainty in the determination of this parameter.

To estimate the lifespan of a structural element like a beam or a column, affected by corrosion, different steps must be taken.

(i) First, the time when corrosion is likely to start (initiation time, $t_{i}$ ) must be obtained. To do this the model in the MC2010 is applied.

(ii) Secondly, the propagation of corrosion with time, this is, the loss of reinforcement bars section with time, must be calculated. This phenomenon depends on the corrosion rate, $v_{\text {corr }}$. This value must be measured and is not constant with time. However, when no data are available, it can be approximated by the values from Table 2 adapted from [41] depending on the Eurocode 2 [37] exposure classes. The standard deviation of this parameter is taken from [42] to make an estimation.

Table 2 Representative values for Vcorr for the Eurocode 2 exposure classes [41]

\begin{tabular}{ll}
\hline Exposure class & $\mathrm{V}_{\text {corr }}[\mu \mathrm{m} /$ year $]$ \\
\hline $\mathrm{XC} 1$ & 0 \\
$\mathrm{XC} 2$ & 4 \\
$\mathrm{XC} 3$ & 2
\end{tabular}


(iii) Thirdly, an admissible limit in the structural performance must be defined. This is the second improvement we have made to the method proposed by [51]. [51] leave the selection of the admissible limit entirely to the technician, whereas we propose the use of the partial factor method and its adaptation to existing structures [43]. Next, we explain this method.

Usually, the design value of the beam's capacity is bigger than the required capacity. This is because reinforcing bars diameters are standardised and a combination of them must be chosen to, at least, overcome the required capacity. In the corrosion process the diameter of the reinforcing bars decreases with time. The admissible limit is set at the moment when the design value of the resistance of the beam is strictly equal to the supported bending moment.

The design of structures according to Eurocodes is based on the concept of limit states and their verification by the partial factor method [43]. In the structural assessment process there are uncertainties related to the determination of the loads, material properties, geometry, etc. To obtain the design value, different partial safety factors are introduced that need to be applied to materials properties and loads to ensure a certain reliability level. These factors are defined in the regulation in the case of new structures. For concrete and steel, they are 1.5 and 1.15 , respectively.

When existing structures are assessed, the uncertainty regarding the available information is different. Therefore, to ensure the same reliability level than in new structures, the value of the partial factors are different. The same target reliability index $(\beta=3.8)$ has been assumed for both existing and new buildings. Assuming that the tests of material properties yield to coefficients of variation $\mathrm{V}_{\mathrm{c}}=0.15$ and $\mathrm{V}_{\mathrm{s}}=0.05$ [43] and the variability of geometrical uncertainties is insignificant, material factors for concrete and steel are 1.353 and 1.097 , respectively.

(iv) Finally, iterative calculation must be done considering in every step the appropriate diameter of the rebar, according to degradation models. To do this, as already explained, $t_{i}$ and $v_{c o r r}$ are needed. Those are not deterministic values but can be described by means of a normal distribution defined by a mean value and a standard deviation. To assess the mean and standard deviation of the final result from the structural calculation, the structural model is approximated to a quadratic Taylor series.

The time when the admissible limit is reached is taken as the lifespan value of the analyzed building. The lifespan of $\mathrm{R}$ is the difference between the lifespan of the existing building and the time when the 
refurbishment is done. This is because the refurbishment that is considered in this paper does not improve the structure but just the building's thermal performance.

\subsection{LCA}

LCA methodology is applied to evaluate four solutions: SR, PR, SD\&N, and PD\&N. The alternatives are evaluated according to the Global Warming Potential (GWP) indicator, based on 2007 IPCC v1.02 methodology, and using the Ecoinvent (v2.2) database [44] adapted to the Spanish electric mix of 2017, with the software tool EQUER [45]. This indicator is chosen because it is among the most widely used [9], as in [10,11].

The functional unit of these LCAs is housing 80 adults in a collective apartment building of $1257.44 \mathrm{~m}^{2}$ living area, maintaining the architectural configuration of a 60 years old existing building, ensuring at least the fulfilment of the current energy demand regulation, during the lifespan of the building. The reference flow corresponds to $1 \mathrm{~m}^{2}$ and 1 year.

The reference study period corresponds to the period from the renovation or construction work until the end of life of the structure. In every alternative (SR, PR, SD\&N, PD\&N) the estimated lifespan is considered.

The common hypotheses in the LCA include:

(i) No transport of occupants and no household waste is included in the studied system.

(ii) Water consumption (per person and day): Hot water 401, Cold water 1001.

(iii) Constant electric mix (22\% nuclear, 33\% renewable, $17 \%$ carbon and $28 \%$ gas); grid losses $9 \%$.

(iv) Surplus of materials during construction: $5 \%$.

(v) Mains water efficiency: $80 \%$

(vi) Transport distance for materials: Production site to construction site, $100 \mathrm{~km}$; site to recycling, $100 \mathrm{~km}$; site to inert landfill and to incineration, $20 \mathrm{~km}$.

Building materials quantities are derived from the geometry and composition of walls, floors and roof. Equipment is also considered (boiler, cooling system and solar thermal panels). Besides, the following building services materials are added, including plumbing (sanitary equipment, drinking water and wastewater system), electrical and telecommunication services. We proceeded by considering fixed ratios of these elements per $\mathrm{m}^{2}$ of floor (Table 3 ). 
Table 3 Materials ratios considered plumbing and electricity

\begin{tabular}{lll}
\hline Element & Unit & Ratio per $\mathrm{m}^{2}$ \\
\hline Copper & $\mathrm{kg}$ & $4,36 \mathrm{E}-01$ \\
Steel & $\mathrm{kg}$ & $1,31 \mathrm{E}+00$ \\
PVC & $\mathrm{kg}$ & $2,72 \mathrm{E}-01$ \\
Ceramic & $\mathrm{kg}$ & $2,50 \mathrm{E}+00$ \\
Polyethylene & $\mathrm{kg}$ & $6,50 \mathrm{E}-01$ \\
3-conductor cable & $\mathrm{m}$ & $6,25 \mathrm{E}+00$ \\
\hline
\end{tabular}

In relation to the end of life stage reinforced concrete and metals are considered to be recyclable in order to follow the European Waste Directive 2008/98/CE [46] that imposes to recycle 70\% of building related waste. Although they are not being totally recycled in Spain nowadays [47], we make the assumption that in the future, when the demolition stage takes place, this will have changed according to this regulation. Wood and plastics are considered to be incinerated, and the rest of materials landfilled.

\subsection{Economical aspects}

To achieve efficient buildings that are also affordable from an economical point of view, is an important issue. This is especially relevant in the case of building refurbishment if the purpose is to increase the refurbishment rate of the building stock in Europe. In this paper this is analysed in a simplified way.

To calculate the initial construction costs, the CYPE database [48] for construction prices in Spain is used. This database makes a distinction in the prices depending on the type of work (refurbishment or new building) and the location in Spain.

To calculate the operational costs, the gas natural and electricity prices are taken as an average of the prices offered today by the main energy distributors in Spain. The prices considered are the ones depending on consumption, but not the fixed ones of the energy price corresponding to power, taxes, etc. This results in $0.13 € / \mathrm{kWh}$ for electricity and $0.05 € / \mathrm{kWh}$ for natural gas.

\section{Results and discussion}

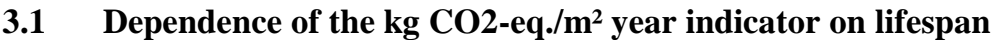

Prior to estimating the lifespan, we have made a theoretical study of the impacts of five solutions along a time period of 150 years considering an existing building of 50 years old. In Fig. 1 the $\mathrm{kg} \mathrm{CO}_{2}$-eq. $/ \mathrm{m}^{2}$ of the different solutions are plotted. 


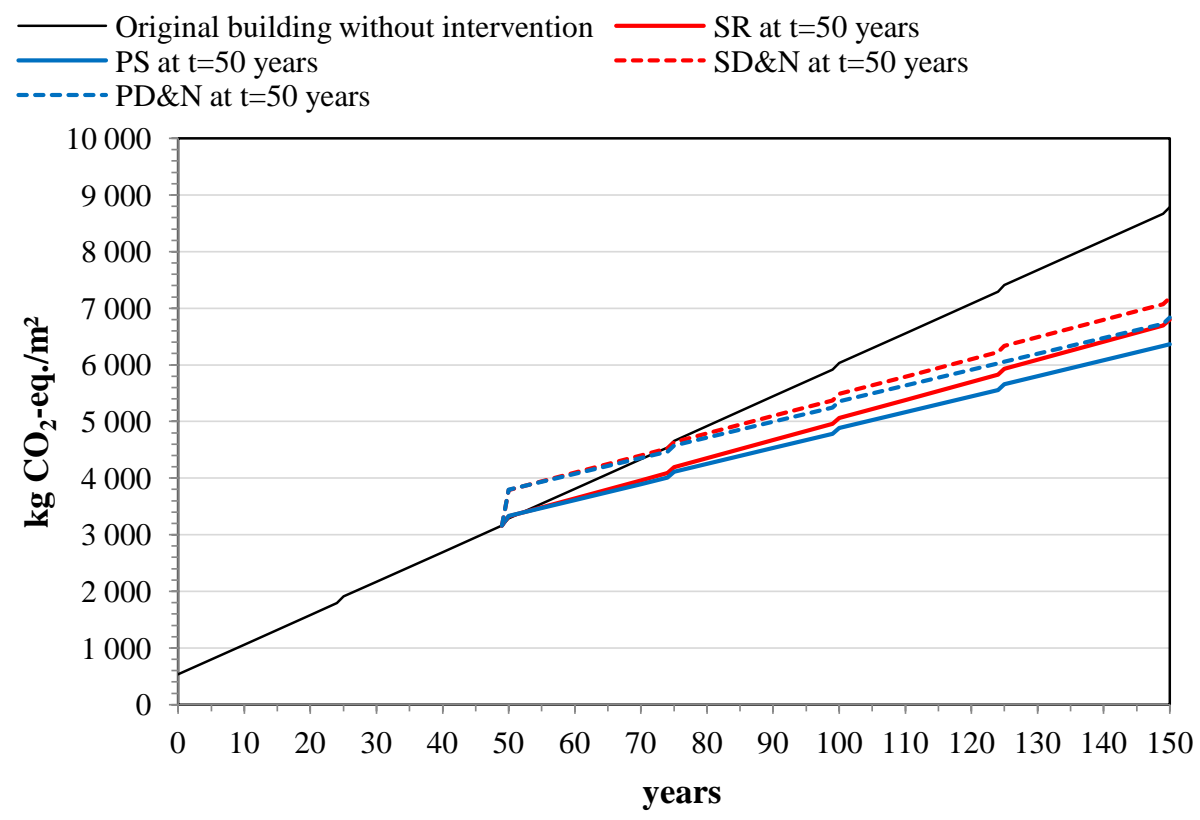

Fig. $1 \mathrm{~kg} \mathrm{CO}$-eq. $/ \mathrm{m}^{2}$ of the original building and different intervention alternatives at $\mathrm{t}=50$ years: $\mathrm{SR}, \mathrm{PR}, \mathrm{SD} \& \mathrm{~N}$ and $\mathrm{PD} \& \mathrm{~N}$

As can be seen in Fig. 1 depending on the year of analysis, the best solution would be different. For example, after a time lapse of 50 years since the intervention both types of $\mathrm{R}$ obtain better results than D\&N. In contrast, if a time lapse of 150 years is considered, SR has equivalent impact to PD\&N. This type of analysis has the implicit assumption that $\mathrm{R}$ and $\mathrm{D} \& \mathrm{~N}$ have the same lifespan. This is usual practice in comparative LCA of R and D\&N. However, this is not likely to happen.

The total amount of $\mathrm{kg} \mathrm{CO}$-eq. $/ \mathrm{m}^{2}$ depends on the number of years considered. For this reason, the results are usually annualised and transformed into $\mathrm{kg} \mathrm{CO}_{2}$-eq. $/ \mathrm{m}^{2}$.year. This allows to compare different stages and different buildings. However, this does not correct the problem of different lifespans. Even if the results are annualised, the value of this indicator is still strongly dependent on time, as can be seen in Fig. 2. When the considered lifespans are up to 200 years the value of the indicator is sensitive to time. A nearly constant tendency is only reached after long periods of time that do not correspond to the commonly used lifespans in the LCA of buildings. 


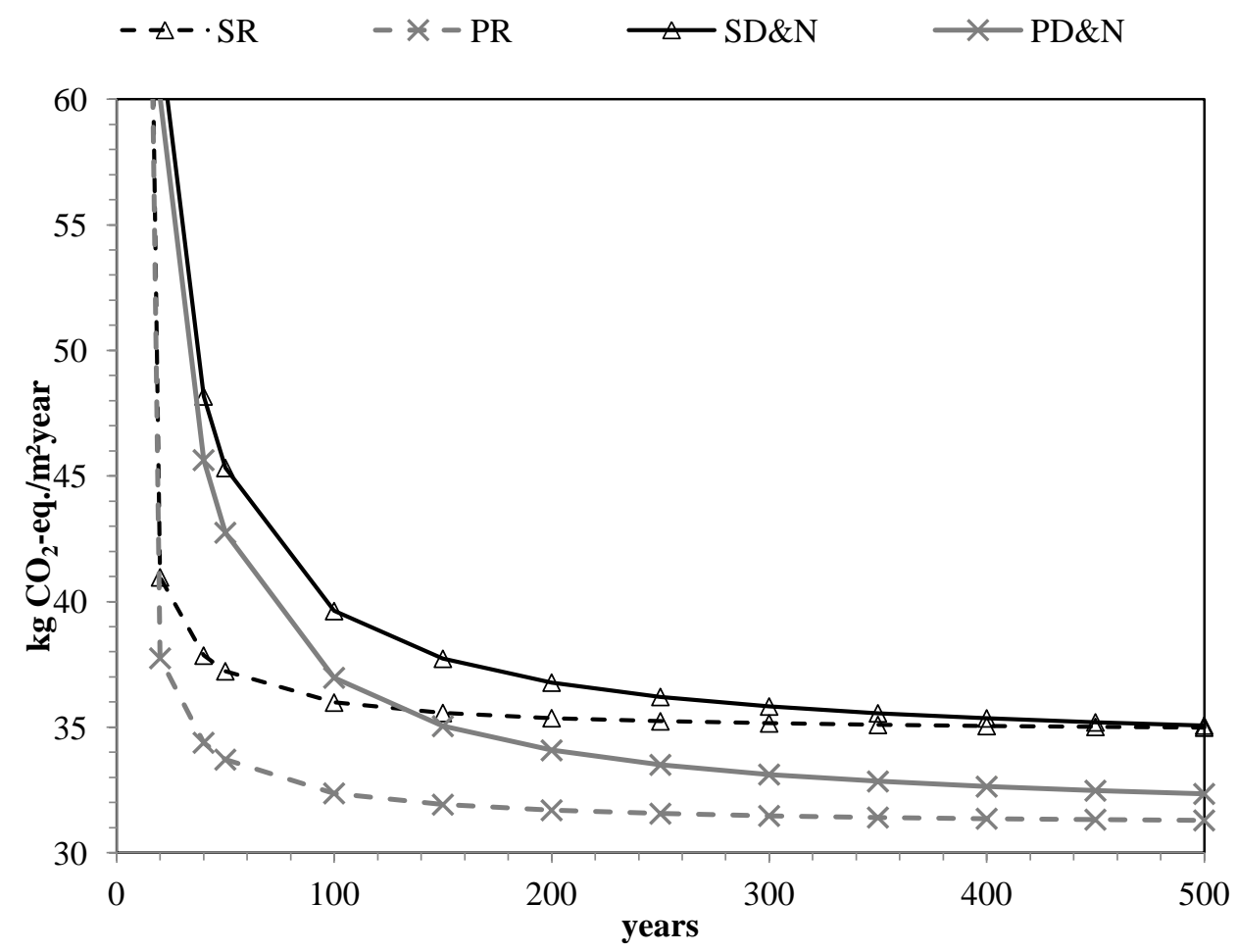

Fig. 2 GWP indicator (kg CO2-eq./m² year) depending on the analyzed years

In addition, when comparing $\mathrm{R}$ and $\mathrm{D} \& \mathrm{~N}$, the lifespan of the refurbished and the new building will not probably be the same. It is reasonable to think that a new building will have a longer lifespan than a similar one built 60 years ago. This is because the new building will comply with current regulation, and therefore will consider phenomena that were not even known before (as AAR) and will include strong control procedures. Additionally, if the same lifespan is considered for both $\mathrm{R}$ and $\mathrm{D} \& \mathrm{~N}$, it is as if the opposite assumption was done (the existing buildings lasts longer), because in R 50 years have already elapsed.

For this reason, we consider that estimating lifespans is necessary to obtain more robust results in LCAs of buildings.

\subsection{Lifespan results}

According to the methodology exposed in 2.2, the structural capacity decreases with time. In Fig. 3, the case of the existing building is presented. The structural element, in this case, a beam of the original building, has an initial bending resistance of $144.45 \mathrm{kN} \cdot \mathrm{m}$, in design value. A final resistance of 140 $\mathrm{kN} \cdot \mathrm{m}$ is considered to be the admissible limit in this case study. The admissible limit is reached no before than 80.5 years with a $25 \%$ of probability, no before than 94.45 years with a $50 \%$ of probability (mean value) or no before 108.4 with a $75 \%$ of probability. 


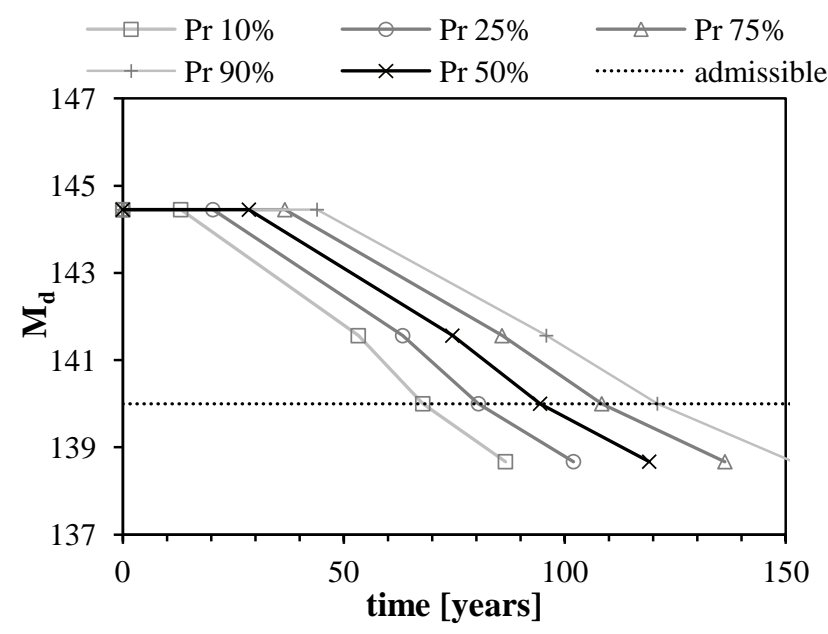

Fig. 3 Decrease of the bending resistance of the original building beam with time

In Table 4 the values of lifespan for the different structural elements of both the original and the new building are shown.

Table 4 Calculated lifespan data depending on the element

\begin{tabular}{|c|c|c|c|c|c|c|c|c|}
\hline & \multicolumn{3}{|c|}{$t_{i}$ [years] } & \multicolumn{3}{|c|}{$v_{\text {corr }}[\mathrm{mm} / \mathrm{año}]$} & \multicolumn{2}{|c|}{ Serivce life [years] } \\
\hline & mean & $\sigma$ & Dist. & mean & $\sigma$ & Dist. & mean & $\sigma$ \\
\hline \multicolumn{9}{|c|}{ Original building 1956} \\
\hline Exterior beam & 28.54 & 12.09 & Normal & 0.005 & 0.00125 & Normal & 94.45 & 20.77 \\
\hline Sanitary slab beam & 33.32 & 13.65 & Normal & 0.004 & 0.00100 & Normal & 125.60 & 28.76 \\
\hline Interior beam & 22.04 & 9.03 & Normal & 0 & 0 & Normal & - & - \\
\hline Roof beam & 33.32 & 13.65 & Normal & 0.002 & 0.00050 & Normal & 204.25 & 44.34 \\
\hline \multicolumn{9}{|l|}{ New building 2018} \\
\hline Exterior beam & 40.80 & 17.54 & Normal & 0.005 & 0.00125 & Normal & 210.03 & 47.93 \\
\hline Sanitary slab beam & 47.48 & 19.70 & Normal & 0.004 & 0.00100 & Normal & 249.5 & 53.78 \\
\hline Interior beam & 31.40 & 13.03 & Normal & 0 & 0 & Normal & - & - \\
\hline Roof beam & 47.48 & 19.70 & Normal & 0.002 & 0.00050 & Normal & 456.5 & 104.18 \\
\hline
\end{tabular}

As exposed in 2.2, the smaller value (the most adverse) is chosen as the structure lifespan. In Table 5 the values actually used for the lifespan of the whole building for the different alternatives are presented. In real practice, physical degradation is not the only cause of building demolition. In fact, it is not even the most common, being the main cause the subjective perception (44\%), followed by change in use (26\%), according to [49]. Deterioration was the cause of only $17 \%$ of the projects [49].

In the case of Spain, statistical lifespan data, depending on their construction period, can be found in Rincón et al. [50]. This value is also included in Table 5. 
Table 5 Lifespan results

\begin{tabular}{llll}
\hline & \multicolumn{2}{l}{ Estimated lifespan } & $\begin{array}{l}\text { Statistical lifespan } \\
{[50]}\end{array}$ \\
& mean & deviation & Deterministic \\
\hline Original building & 94.45 & 20.77 & 90 \\
SR at $\mathrm{t}=60$ & 34.45 & 20.77 & 30 \\
PR at $\mathrm{t}=60$ & 34.45 & 20.77 & 30 \\
SD\&N & 210.03 & 47.93 & 80 \\
PD\&N & 210.03 & 47.93 & 80 \\
\hline
\end{tabular}

As can be seen in Table 5, the new building has a lifespan 2.2 times greater than the original one, for the same structural reliability level. If we also take into account that a part of the lifespan of the existing building has already elapsed at the time of refurbishment, the lifespan of the new building is about 6 times longer than the refurbished, in this case study.

\subsection{Results obtained taking into account the calculated value of lifespan}

In Fig. 4 the value of $\mathrm{kg} \mathrm{CO}_{2} / \mathrm{m}^{2}$.year is shown taking into account a lifespan of: (a) 100 years for all the solutions (similar to usual practice), (b) the specific estimated lifespan for each of the solutions, and (c) the statistical data of lifespan according to [50], which is also different for each solution. In Fig. 4 b), the results obtained considering the mean value of the lifespan, the mean plus its standard deviation and the mean minus its standard deviation are displayed.

a)

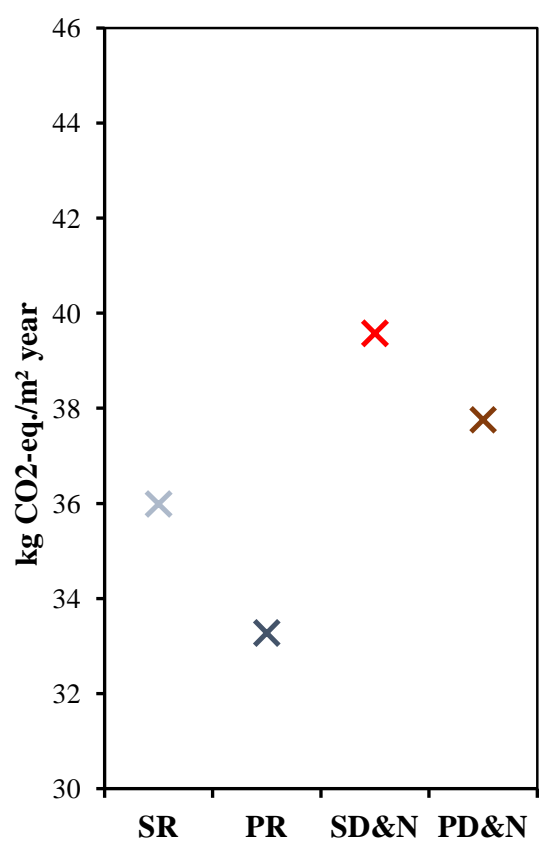

b)

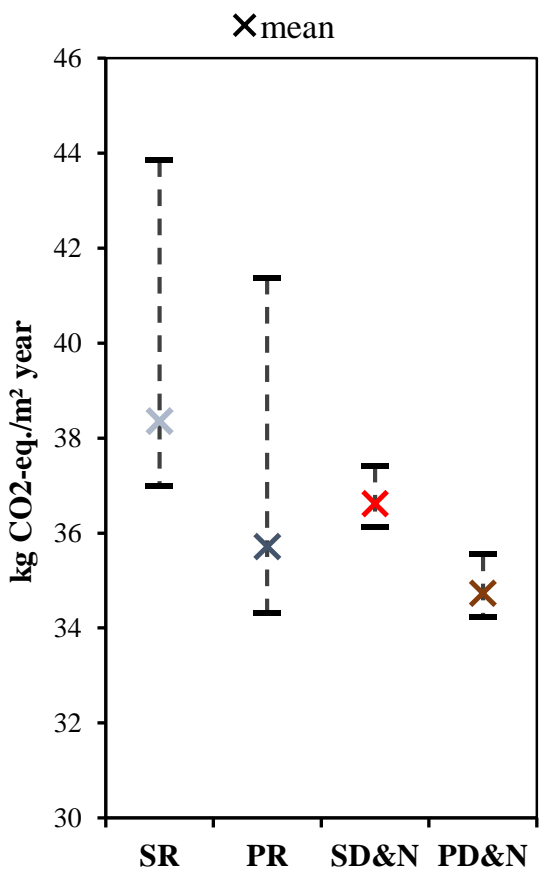

c)

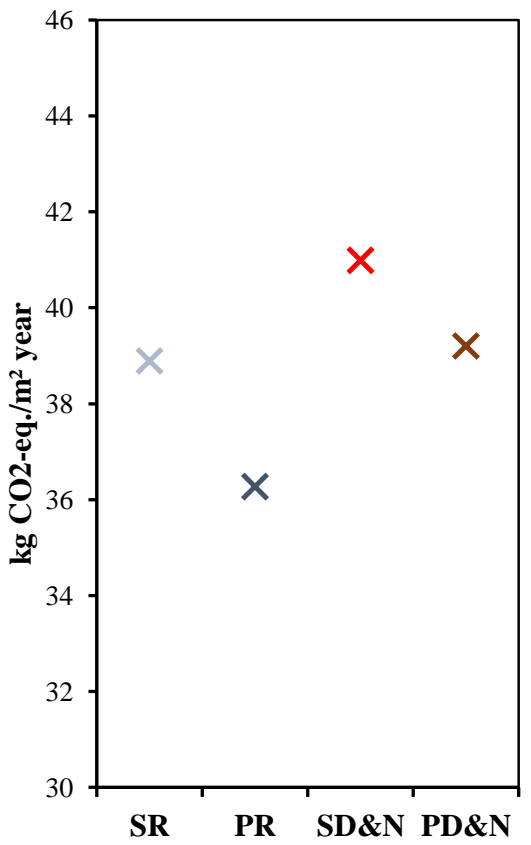

Fig. $4 \mathrm{~kg} \mathrm{CO} 2$-eq. $/ \mathrm{m}^{2}$ year taking into account: (a) 100 years for all the alternatives; (b) their specific lifespan according to Table 5; and (c) their statistical lifespan according to [50] 
According to these results, when the same lifespan is considered (Fig. 4a), PR is, by large, the best alternative, but this is not a reliable result as discussed before. PR also results to be the best option when the statistical values of lifespan are considered (Fig. 4c), although the difference with the other alternatives is significantly reduced. According to Fig. $\mathbf{4 b}$ PR is the second best option. Therefore, we can conclude that PR is one of the best alternatives from the point of view of $\mathrm{CO}_{2}$ emissions.

PD\&N obtains the best results when the estimated lifespans are considered (Fig. $\mathbf{4 b}$ ). However, it requires to ensure a very long lifespan (around 210 years) which is very difficult to guarantee in practice.

SR is the worst solution when lifespans are estimated (Fig. $\mathbf{4 b}$ ). This reveals that SR requires a $\mathrm{CO}_{2}$-eq. investment which does not provide an optimal performance of the building and its useful life is short. Refurbishment should aim to reach passive standards to optimise the $\mathrm{CO}_{2}$-eq. investments.

The estimated value of lifespan has an uncertainty that derives from the degradation model. This uncertainty has different effects in the results of the $\mathrm{kg} \mathrm{CO}_{2}$-eq. $/ \mathrm{m}^{2}$.year indicator. In the case $\mathrm{R}$ solutions, the influence of this uncertainty in the results is higher because the lifespan is shorter. This is aligned with the findings in Fig. 2. For short lifespans, the value of the indicator significantly varies with little time increments. This is because the contribution of the construction and demolition stages to the global impact is high. On the contrary, in the case of new buildings, as their lifespan is long, the value of the indicator is almost established, and it is not so sensitive to changes. In the case of the new buildings, the uncertainty is produced mostly because of the huge difference between the estimated physical lifespan and the statistical data rather than because of the durability model. This statistical data takes into account that buildings are often demolished for reasons other than degradation.

\subsection{Economic consideration}

Table 6 shows the costs at different stages for the different alternatives. The construction costs include materials, machinery and manpower. Taxes, other expenses like technicians' fees, waste management, etc. are not taken into account. 
Table 6 Cost of the diferent intervention alternatives

\begin{tabular}{lllcccc}
\hline & $\begin{array}{l}\text { Construction } \\
{\left[€ / \mathrm{m}^{2}\right]}\end{array}$ & stage & $\begin{array}{l}\text { Use stage } \\
{\left[€ / \mathrm{m}^{2} \cdot \text { year }\right]}\end{array}$ & $\begin{array}{l}\text { Use stage cooling } \\
{\left[€ / \mathrm{m}^{2} \cdot \text { year }\right]}\end{array}$ & $\begin{array}{c}\text { Total use } \\
{\left[€ / \mathrm{m}^{2} \cdot \text { year }\right]}\end{array}$ & $\begin{array}{c}\text { stage } \\
\text { SR }\end{array}$ \\
391.00 & 1.68 & 0.48 & 2.16 \\
$\mathrm{PR}$ & 439.43 & 0.84 & 0.88 & 1.72 \\
$\mathrm{SD \& N}$ & 690.39 & 1.52 & 0.41 & 1.93 \\
PD\&N & 735.98 & 0.84 & 0.82 & 1.66 \\
Demolition & 57.27 & - & - & - \\
\hline
\end{tabular}

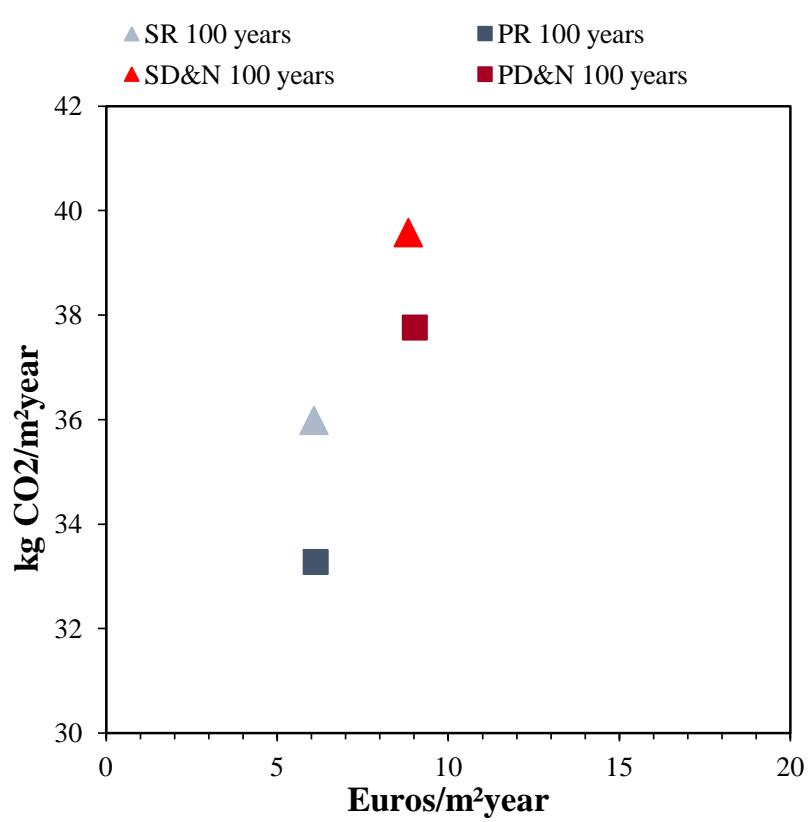

Fig. 5 Relation between cost and $\mathrm{CO}_{2}$ emissions when a same lifespan of 100 years is considered for all the solutions

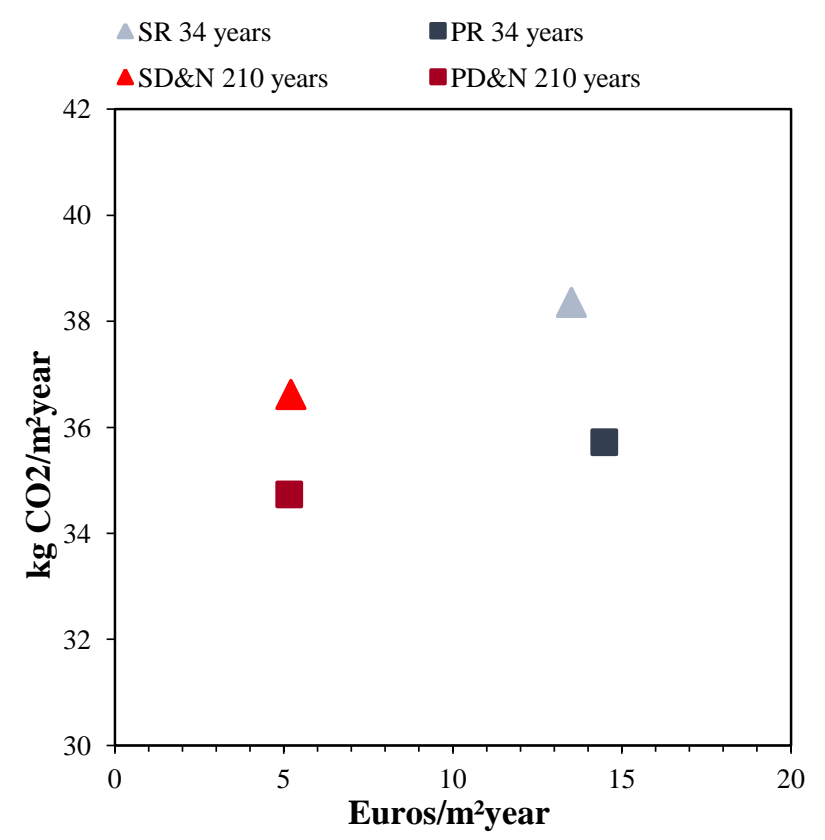

Fig. 6 Relation between cost and $\mathrm{CO}_{2}$ emissions when the estimated lifespans are considered

As can be seen in Table 6, the cost of $D \& N$ is considerably higher than $R$ for this case study. As a counterpart, in both PR and PD\&N, the use stage costs of heating are the lowest. In the case of cooling, the cost is higher for PR and PD\&N, because the building is more insulated and just the night ventilation proposed in the regulation is considered.

Fig. 5 and Fig. 6 show the relation between cost and $\mathrm{CO}_{2}$ emissions when a same lifespan of 100 years is considered for all the solutions and when the estimated lifespans are used instead, respectively.

According to Fig. 5, when the same lifespan is considered, there is a big difference between R and D\&N. New construction results to be not only the worst option from a $\mathrm{CO}_{2}$ emissions point of view, but also it results to be the most expensive alternative. PR results to be, by large, the most cost-effective solution. 
However, if the emissions and the costs of every solution are evaluated considering their estimated lifespans (Fig. 6) the results considerably differ. In this case, both SD\&N and PD\&N result to be cheaper per year, as the construction cost is annualised in many years. In fact, if the estimated lifespan value is used, the most cost-effective solution results to be PD\&N. However, in this case the long lifespan of 210 years must also be ensured as mentioned before, and the initial cost of construction is, in most cases, a decisive parameter and refurbishment options require fewer initial investments.

\subsection{Limits of the study}

Some limits must be noted in this study.

The estimated lifespans can be considered optimistic, since degradation is not the main cause of building demolition, as already exposed. In addition, not all the degradation models have been included but just corrosion, which is the most common one. However, the results illustrate the durability of reinforced concrete structures considering its physical potential. This gives us an idea of the environmental benefit margin compared to usual demolition trends.

It must also be noted that results are case dependent as each building has its own durability depending on the concrete, the exposure conditions, etc. The available options both for refurbishment and new building are multiple. Anyhow, the methodology proposed can be extended to other cases.

Static life cycle inventory data were used, but there is uncertainty regarding their long-term values (e.g. electricity mix, production processes, etc.). This long-term uncertainty does exit also regarding energy demand, as climate change can lower the heating loads and increase the cooling ones. In addition, building thermal loads could be different by incorporating solar blinds or increasing night ventilation. In this study we considered the operational conditions of current regulations in Spain.

\section{Conclusions}

In this paper refurbishment $(\mathrm{R})$ versus demolition and new building $(\mathrm{D} \& \mathrm{~N})$ have been evaluated from an environmental point of view, proposing a new approach that allows to estimate and use the different lifespans of the buildings in a comparative LCA. Two energy performance levels have been analysed, standard (S) and passive (P), resulting in four alternatives: SR, PR, SD\&N, PD\&N. Economic assessment has also been addressed in a simplified way. 
Lifespan is a fundamental aspect in the LCA of buildings, that greatly influences the results. It becomes still more important when comparing refurbishment (above all, of old buildings) and new buildings because their durability may be very different. By not considering the lifespan in an appropriate way the most durable buildings are penalized. We have shown the different results obtained by considering a similar lifespan for refurbished and new buildings, which is the common practice, and by estimating the lifespans of each solution. The different in lifespans is up to 176 years in our case study. The results show that these different lifespans can alter the order of preference of the solutions from an environmental point of view. Therefore, estimating a value for this parameter as reliable as possible is a fundamental task in the LCA of buildings. A broadly accepted methodology that allows to estimate the buildings lifespan does not exist yet. In this paper an approximation to this problem has been defined but more research is required in this direction.

In our case study, in terms of $\mathrm{CO}_{2}$ equivalent emissions, the alternative PD\&N obtains the best result, slightly better than PR, but it requires to ensure a very long lifespan which is highly unlikely to happen according to current practices. Because of this, PR appears as the best choice from the environmental point of view. SR does not yield optimal results and, therefore, refurbishment should aim to reach passive standards.

The economic analysis shows that D\&N alternatives are more cost-efficient when considering the annualized costs, due to their longer durability, but not from the initial investments point of view.

This paper reveals the importance of the lifespan to get economic and environmental benefits and render cost-effectiveness in the long term to the building sector. In the case of the existing buildings an important objective should be to extend their lifespan by means of improving their structure, as suggested in [3]. In the case of new buildings, the objective should be to ensure their potential durability by changing current human tendencies of early substitution.

\section{Acknowledgements}


This work was supported by the Spanish Ministry of Education, Culture and Sports, through a FPU research grant [grant FPU15/01069] and the Research Group GIA [T37_17R] of the University of Zaragoza (Spain).

\section{References}

[1] $\operatorname{COM(2003)~302,~COMMUNICATION~FROM~THE~COMMISSION~TO~THE~COUNCIL~AND~}$ THE EUROPEAN PARLIAMENT Integrated Product Policy Building on Environmental LifeCycle Thinking, n.d. doi:10.1117/1.NPh.2.2.025001.

[2] European Commission, Commission Recommendation (EU) 2016/1318, 2016.

[3] B. Palacios-Munoz, L. Gracia-Villa, I. Zabalza-Bribián, B. López-Mesa, Simplified structural design and LCA of reinforced concrete beams strengthening techniques, Eng. Struct. 174 (2018) 418-432. doi:10.1016/j.engstruct.2018.07.070.

[4] I. Zabalza Bribián, A. Aranda Usón, S. Scarpellini, Life cycle assessment in buildings: State-ofthe-art and simplified LCA methodology as a complement for building certification, Build. Environ. 44 (2009) 2510-2520. doi:10.1016/j.buildenv.2009.05.001.

[5] I. Zabalza Bribián, A. Valero, A. Aranda Usón, E. Llera, Methodological aspects and design implications to achieve life cycle low emission buildings. A case study: LCA of a new university building, Strojarstvo. (2013).

[6] O. Ortiz-Rodríguez, F. Castells, G. Sonnemann, Life cycle assessment of two dwellings: One in Spain, a developed country, and one in Colombia, a country under development, Sci. Total Environ. 408 (2010) 2435-2443. doi:10.1016/j.scitotenv.2010.02.021.

[7] R.M. Cuéllar-Franca, A. Azapagic, Environmental impacts of the UK residential sector: Life cycle assessment of houses, Build. Environ. $54 \quad$ (2012) 86-99. doi:10.1016/j.buildenv.2012.02.005.

[8] F. Nemry, A. Uihlein, C.M. Colodel, C. Wetzel, A. Braune, B. Wittstock, I. Hasan, J. Kreißig, N. Gallon, S. Niemeier, Y. Frech, Options to reduce the environmental impacts of residential buildings in the European Union-Potential and costs, Energy Build. 42 (2010) 976-984. 
doi:10.1016/j.enbuild.2010.01.009.

[9] A. Vilches, A. Garcia-Martinez, B. Sanchez-Montañes, Life cycle assessment (LCA) of building refurbishment: A literature review, Energy Build. (2017). doi:dx.doi.org/10.1016/j.enbuild.2016.11.042.

[10] A.A. Famuyibo, A. Duffy, P. Strachan, Achieving a holistic view of the life cycle performance of existing dwellings, Build. Environ. 70 (2013) 90-101. doi:10.1016/j.buildenv.2013.08.016.

[11] H. Mohammadpourkarbasi, S. Sharples, Eco-Retrofitting Very Old Dwellings: Current and Future Energy and Carbon Performance for Two Uk Cities, in: PLEA 2013 Sustain. Archit. a Renew. Futur., Munich (Germany), 2013.

[12] B. Peuportier, Assessment and design of a renovation project using life cycle analysis and Green Building Tool, in: T.D. Pettersen (Ed.), Proc. Int. Conf. - Challenge, Knowledge, Solut., in-house publishing, Orlo, 2002: pp. 352-357.

[13] G. Assefa, C. Ambler, To demolish or not to demolish: Life cycle consideration of repurposing buildings, Sustain. Cities Soc. 28 (2017) 146-153. doi:10.1016/j.scs.2016.09.011.

[14] G. Ding, Demolish or refurbish-Environmental benefits of housing conservation, Australas. J. Constr. Econ. Build. 13 (2013) 18-34. doi:10.5130/ajceb.v13i2.3322.

[15] M.D. Alba-Rodríguez, A. Martínez-Rocamora, P. González-Vallejo, A. Ferreira-Sánchez, M. Marrero, Building rehabilitation versus demolition and new construction: Economic and environmental assessment, Environ. Impact Assess. Rev. $66 \quad$ (2017) 115-126. doi:10.1016/j.eiar.2017.06.002.

[16] Y. Schwartz, R. Raslan, D. Mumovic, The life cycle carbon footprint of refurbished and new buildings - A systematic review of case studies, Renew. Sustain. Energy Rev. 81 (2018) 231241. doi:10.1016/j.rser.2017.07.061.

[17] W. Pan, K. Li, Y. Teng, Rethinking system boundaries of the life cycle carbon emissions of buildings, Renew. Sustain. Energy Rev. 90 (2018) 379-390. doi:10.1016/j.rser.2018.03.057. 
[18] H. Islam, M. Jollands, S. Setunge, Life cycle assessment and life cycle cost implication of residential buildings - A review, Renew. Sustain. Energy Rev. 42 (2015) 129-140. doi:10.1016/j.rser.2014.10.006.

[19] K. Adalberth, A. Almgren, E.H. Petersen, Life-Cycle Assessment of Four Multi-Family Buildings, Int. J. Low Energy Sustain. Build. (2001).

[20] C.D. Frenette, C. Bulle, R. Beauregard, A. Salenikovich, D. Derome, Using life cycle assessment to derive an environmental index for light-frame wood wall assemblies, Build. Environ. 45 (2010) 2111-2122. doi:10.1016/j.buildenv.2010.03.009.

[21] U. Iyer-Raniga, J.P.C. Wong, Evaluation of whole life cycle assessment for heritage buildings in Australia, Build. Environ. 47 (2012) 138-149. doi:10.1016/j.buildenv.2011.08.001.

[22] O. Ortiz, C. Bonnet, J.C. Bruno, F. Castells, Sustainability based on LCM of residential dwellings: A case study in Catalonia, Spain, Build. Environ. (2009). doi:10.1016/j.buildenv.2008.05.004.

[23] K. Adalberth, Energy use during the life cycle of single-unit dwellings: Examples, Build. Environ. 32 (1997) 321-329. doi:10.1016/S0360-1323(96)00069-8.

[24] I.M. Johnstone, Energy and mass flows of housing: A model and example, Build. Environ. 36 (2001) 27-41. doi:10.1016/S0360-1323(99)00065-7.

[25] H. Bergsdal, H. Bratteb $\varnothing$, R.A. Bohne, D.B. Müller, Dynamic material flow analysis for Norway’s dwelling stock, Build. Res. Inf. 35 (2007) 557-570. doi:10.1080/09613210701287588.

[26] M. Aksözen, U. Hassler, N. Kohler, Reconstitution of the dynamics of an urban building stock, Build. Res. Inf. (2017). doi:10.1080/09613218.2016.1152040.

[27] A. Haapio, Service Life of a Building in Environmental Assessment of Buildings, (2008).

[28] J. Monjo Carrió, Durability vs Vulnerability, Inf. La Construcción. 59 (2007) 43-58. doi:10.3989/ic.2007.v59.i507.531.

[29] H. Budelmann, A. Holst, A. Wachsmann, Durability related life-cycle assessment of concrete 
structures: Mechanisms, models, implementation, in: F. and B. Strauss (Ed.), Life-Cycle Sustain. Civ. Infrastruct. Syst., Taylor and Francis Group, 2013: pp. 75-86.

[30] V.L. Ta, S. Bonnet, T. Senga Kiesse, A. Ventura, A new meta-model to calculate carbonation front depth within concrete structures, Constr. Build. Mater. 129 (2016) 172-181. doi:10.1016/j.conbuildmat.2016.10.103.

[31] F. Pedrosa, C. Andrade, Corrosion induced cracking: Effect of different corrosion rates on crack width evolution, Constr. Build. Mater. $133 \quad$ (2017) 525-533. doi:10.1016/j.conbuildmat.2016.12.030.

[32] K. Tuutti, Corrosion of steel in concrete, Swedish Cem. Concr. Res. Inst. (1982) 469. doi:10.4324/9780203414606_chapter_2.

[33] S.W. Tang, Y. Yao, C. Andrade, Z.J. Li, Recent durability studies on concrete structure, Cem. Concr. Res. 78 (2015) 143-154. doi:10.1016/j.cemconres.2015.05.021.

[34] Ministry of Development (Spain), Proyecto de Real Decreto por el que se modifica el Real Decreto 314/2006, de 17 de marzo, por el que se aprueba el Código Técnico de la Edificación_Anejo I DB HE Ahorro de Energía, (2018) 1-51.

[35] Passive House Institute, Criteria for the Passive House, EnerPHit and PHI Low Energy Building Standard, 2016.

[36] B. Peuportier, I. Blanc Sommereux, Simulation tool with its expert interface for the thermal design of multizone buildings, Int. J. Sol. Energy. 8 (1990) 109-120.

[37] European Union, EN-1992-1-1: Eurocode 2: Design of concrete structures - Part 1-1 : General rules and rules for buildings, The European Union Per Regulation 305/2011, Directive 98/34/EC, Directive 2004/18/EC, 2004. papers2://publication/uuid/1B0960C1-28E7-4B6A-ADFE19C0455EDFD3.

[38] I.E. Torroja, Instrucción H.A. 61 Especial para estructuras de hormigón armado, 1961.

[39] Ministry of Development (Spain), Instrucción de Hormigón Estructural (EHE-08), 2008. 
doi:10.1017/CBO9781107415324.004.

[40] The International Federation for Structural Concrete (fib), Model Code 2010, Fib Model Code Concr. Struct. 2010. (2011) 114-148. doi:10.1002/9783433604090.ch6.

[41] C. Andrade, Modelos de propagación del deterioro del hormigón, in: REHABEND 2018, Constr. Pathol. Rehabil. Technol. Herit. Manag., University of Cantabria, Cáceres (Spain), 2018: pp. $835-842$.

[42] M. Šomodíková, D. Lehký, J. Doležel, D. Novák, Modeling of degradation processes in concrete: Probabilistic lifetime and load-bearing capacity assessment of existing reinforced concrete bridges, Eng. Struct. 119 (2016) 49-60. doi:10.1016/j.engstruct.2016.03.065.

[43] International Federation for Structural Concrete (fib), Bulletin No. 80. Partial factor methods for existing concrete structures. Recommendation, 2016.

[44] R. Frischknecht, N. Jungbluth, H.-J. Althaus, G. Doka, T. Heck, S. Hellweg, R. Hischier, T. Nemecek, G. Rebitzer, M. Spielmann, Overview and Methodology, ecoinvent report No. 1, Dübendorf, Switzerland, 2004.

[45] B. Polster, B. Peuportier, I. Blanc Sommereux, P. Diaz Pedregal, C. Gobin, E. Durand, Evaluation of the environmental quality of buildings - a step towards a more environmentally conscious design, Sol. Energy. 57 (1996) 219-230.

[46] European Parliament and the Council of the European Union, Directive 2008/98/EC of the European Parliament and of the Council of 19 November 2008 on waste and repealing certain Directives, 2008.

[47] N. Bizcocho Tocón, Aplicación del análisis de ciclo de vida a la gestión de los residuos de construcción, University of Sevilla, 2014. https://idus.us.es/xmlui/handle/11441/56324.

[48] CYPE Ingenieros S.A., Generador de precios de la construcción, España. CYPE Ing. (2016). doi:10.1177/0363546515601381.

[49] B. Marteinsson, Service Life Estimation in the Design of Buildings, University of Gävle, 2005. 
[50] L. Rincón, G. Pérez, L.F. Cabeza, Service life of the dwelling stock in Spain, Int. J. Life Cycle Assess. 18 (2013) 919-925. doi:10.1007/s11367-013-0552-x.

[51] B. Palacios-Munoz, B. López-Mesa, L. Gracia-Villa, Influence of refurbishment and service life of reinforced concrete buildings structures on the estimation of environmental impact_In press, Int. J. Life Cycle Assess. 18 (2019). doi:10.1007/s11367-019-01622-w. 